\title{
The Challenges of Identifying an Oxygenation Index Threshold for Increased Mortality in Pediatric Acute Respiratory Failure
}

The Pediatric Acute Lung Injury Consensus Conference (PALICC) recognizes oxygenation index (OI), a measure of oxygenation based on level of respiratory support, as the primary metric of lung disease severity in defining pediatric ARDS. ${ }^{1}$ Traditionally, OI has been used to guide escalation of respiratory support to high-frequency ventilation $(\mathrm{OI}>20)$ and extracorporeal membrane oxygenation $(\mathrm{OI}>40)^{2,3}$ In this issue of Respiratory CARe, Hammond et $\mathrm{al}^{4}$ report a retrospective, single-center study evaluating the association between mortality and maximum OI during mechanical ventilation among subjects 1 month to $20 \mathrm{y}$ of age who were mechanically ventilated for $>24 \mathrm{~h}$. The authors identify mortality of $6-7 \%$ among those with maximum OI $\leq 17$ compared with $18 \%$ among those with a maximum OI $>17$.

Consistent with recent literature, Hammond et $\mathrm{al}^{4}$ challenge historic OI cut points used for escalation of respiratory support or initiation of extracorporeal support. ${ }^{5,6} \mathrm{~A}$ 2015 analysis of 397 mechanically ventilated children with acute lung injury identified a near doubling in mortality for each step up: OI $<4$ (at risk for pediatric ARDS), 4-8 (mild pediatric ARDS), 8-16 (moderate pediatric ARDS), and $>16$ (severe pediatric ARDS). ${ }^{1}$ Although data aggregated from 6 other studies reveal a stepwise increase in mortality with pediatric ARDS classifications, OI demonstrates poor sensitivity for prospective mortality predictions. ${ }^{1,7}$ In an analysis of 511 subjects with pediatric ARDS, a peak OI $>16$ in the first $3 \mathrm{~d}$ of mechanical ventilation predicted mortality in only $40 \%$ of subjects. ${ }^{1}$

Several potential reasons for the poor predictive ability of OI for mortality among children with pediatric ARDS exist, many of which are well demonstrated in the report by Hammond et al. ${ }^{4}$ First, we must acknowledge the presence of competing risks, or events that preclude the occurrence of the primary event of interest. ${ }^{8}$ For example, critically ill children are at risk of death from a variety of causes, including death from brain injury, but a child who dies from brain injury has no chance of later death due to respiratory failure nor any chance of surviving respiratory

The authors have disclosed no conflicts of interest.

Correspondence: Samantha H Dallefeld MD, Duke University Hospital, DUMC Box 3046, Durham, NC 27710.E-mail: samantha.dallefeld@ duke. edu.

DOI: $10.4187 /$ respcare. 05863 failure. According to Table 1 in Hammond et al, ${ }^{4}$ no nonsurvivors had a primary diagnosis of acute respiratory failure; however, brain injury was either the primary or secondary diagnosis in all 6 non-survivors. Typically, a child

See the Original Study on Page 1249

who dies from brain injury has a lower maximum OI than a child who dies from respiratory failure. ${ }^{9,10}$ Consequently, deaths from brain injury lower the OI associated with mortality, although advanced respiratory support or extracorporeal membrane oxygenation would not have saved such patients. Statistically, this problem can be solved by stratifying the analysis: excluding all children with a non-respiratory diagnosis or a non-respiratory cause of death and evaluating OI versus death from respiratory failure alone. The limited sample size in Hammond et al ${ }^{4}$ prevents such stratification and broader subsequent conclusions about the OI threshold for mortality.

Second, there is good evidence to suggest that a patient's trajectory early in the course of illness may predict outcome, potentially accounting for a patient's response, or lack thereof, to interventions. ${ }^{7,11,12}$ Although Hammond et al ${ }^{4}$ account for this fact by limiting their included population to those mechanically ventilated for $>24 \mathrm{~h}$, mixed models and other statistical methods that accommodate multiple measures over time may improve the predictive capabilities of OI while slightly diminishing the issue of limited sample size.

Third, confounders of the relationship between OI and mortality among children with pediatric ARDS can lead to poor sensitivity of OI for mortality predictions. Several studies report an increased risk of mortality in infants $<1$ y of age $\mathrm{e}^{1,13}$ and in African American and Hispanic patients. ${ }^{14,15}$ Other potential confounders include a primary diagnosis of non-pulmonary sepsis, immunodeficiency, and multi-organ system failure. ${ }^{6,15,16}$ Immunodeficiency in pediatric ARDS is associated with a mortality of up to $95 \%$ for those with a history of bone marrow transplantation or hematologic malignancy, ${ }^{17-19}$ and mortality increases by almost $60 \%$ with 3 organ failures compared with a single organ failure in children with pediatric ARDS. ${ }^{20}$ Hammond et $\mathrm{al}^{4}$ used traditional multivariable logistic regression to account for the potential confounding bias of days of mechanical ventilation, length of hospital stay, and subject age. However, in traditional logistic regression, accuracy and pre- 


\section{EDITORIALS}

cision of regression coefficients decrease with $<10$ outcomes per variable. ${ }^{21}$ Hammond et $\mathrm{al}^{4}$ reported only 6 outcomes (subject deaths). In addition to the high likelihood of unmeasured confounders, this limited number of outcomes prevents us from relying on the results of the regression, particularly as they relate to effecting clinical practice change.

We are fortunate to have low mortality rates in pediatrics, ranging from 2 to $3 \%$ nationwide in the ICU.22 Undoubtedly, Hammond et $\mathrm{al}^{4}$ have taken on an arduous and extremely important task of identifying the point at which escalation of therapy may save additional lives to further decrease mortality in pediatric acute respiratory failure. Although challenges exist in developing large sample sizes, we should remember when conducting analyses of pediatric mortality that there is strength in numbers. Collaboration among centers to obtain adequate sample sizes for prospective and retrospective studies will improve latitude and clinical utility of studies in pediatric critical care medicine. Further, robust statistical analysis of samples both large and small serves to enhance study validity and applicability.

\section{Samantha H Dallefeld MD}

Department of Pediatrics Duke University Medical Center Duke Clinical Research Institute Duke University Durham, North Carolina

Tracy G Spears MS RN Department of Pediatrics Center for Predictive Medicine Duke Clinical Research Institute Duke University Durham, North Carolina

Kanecia O Zimmerman MD MPH Department of Pediatrics Duke University Medical Center Duke Clinical Research Institute Duke University Durham, North Carolina

\section{REFERENCES}

1. Khemani RG, Smith LS, Zimmerman JJ, Erickson S. Pediatric acute respiratory distress syndrome: definition, incidence, and epidemiology: proceedings from the Pediatric Acute Lung Injury Consensus Conference. Pediatr Crit Care Med 2015;16(5 Suppl 1):S23-S40.

2. Khemani RG, Thomas NJ, Venkatachalam V, Scimeme JP, Berutti $\mathrm{T}$, Schneider JB, et al. Comparison of $\mathrm{S}_{\mathrm{pO}_{2}}$ to $\mathrm{P}_{\mathrm{aO}}$ based markers of lung disease severity for children with acute lung injury. Crit Care Med 2012;40(4):1309-1316.

3. Domico MB, Ridout DA, Bronicki R, Anas NG, Cleary JP, Cappon $\mathrm{J}$, et al. The impact of mechanical ventilation time before initiation of extracorporeal life support on survival in pediatric respiratory failure: a review of the Extracorporeal Life Support Registry. Pediatr Crit Care Med 2012;13(1):16-21.
4. Hammond BG, Garcia-Filion P, Kang P, Rao MY, Willis BC, Dalton HJ. Identifying an oxygenation index threshold for increased mortality in acute respiratory failure. Respir Care 2017;62(10):1249-1254.

5. Khemani RG, Conti D, Alonzo TA, Bart RD 3rd, Newth CJ. Effect of tidal volume in children with acute hypoxemic respiratory failure. Intensive Care Med 2009;35(8):1428-1437.

6. Erickson S, Schibler A, Numa A, Nuthall G, Yung M, Pascoe E, Wilkins B. Acute lung injury in pediatric intensive care in Australia and New Zealand: a prospective, multicenter, observational study. Pediatr Crit Care Med 2007;8(4):317-323.

7. Trachsel D, McCrindle BW, Nakagawa S, Bohn D. Oxygenation index predicts outcome in children with acute hypoxemic respiratory failure. Am J Respir Crit Care Med 2005;172(2):206-211.

8. Austin PC, Lee DS, Fine JP. Introduction to the analysis of survival data in the presence of competing risks. Circulation 2016;133(6):601-609.

9. Holland MC, Mackersie RC, Morabito D, Campbell AR, Kivett VA, Patel R, et al. The development of acute lung injury is associated with worse neurologic outcome in patients with severe traumatic brain injury. J Trauma 2003;55(1):106-111.

10. Stewart TC, Alharfi IM, Fraser DD. The role of serious concomitant injuries in the treatment and outcome of pediatric severe traumatic brain injury. J Trauma Acute Care Surg 2013;75(5):836-842.

11. Yehya N, Servaes S, Thomas NJ. Characterizing degree of lung injury in pediatric acute respiratory distress syndrome. Crit Care Med 2015;43(5):937-946.

12. Ruttenstock E, Wright N, Barrena S, Krickhahn A, Castellani C, Desai AP, et al. Best oxygenation index on day 1: a reliable marker for outcome and survival in infants with congenital diaphragmatic hernia. Eur J Pediatr Surg 2015;25(1):3-8.

13. Zhu YF, Xu F, Lu XL, Wang Y, Chen JL, Chao JX, et al. Mortality and morbidity of acute hypoxemic respiratory failure and acute respiratory distress syndrome in infants and young children. Chin Med J 2012;125(13):2265-2271.

14. Erickson SE, Shlipak MG, Martin GS, Wheeler AP, Ancukiewicz M, Matthay MA, et al. Racial and ethnic disparities in mortality from acute lung injury. Crit Care Med 2009;37(1):1-6.

15. Flori H, Dahmer MK, Sapru A, Quasney MW. Comorbidities and assessment of severity of pediatric acute respiratory distress syndrome: proceedings from the Pediatric Acute Lung Injury Consensus Conference. Pediatr Crit Care Med 2015;16(5 Suppl 1):S41-S50.

16. Li Y, Wang Q, Chen H, Gao HM, Zhou T, Qian SY. Epidemiological features and risk factor analysis of children with acute lung injury. World J Pediatr 2012;8(1):43-46.

17. Quasney MW, López-Fernández YM, Santschi M, Watson RS, Pediatric Acute Lung Injury Consensus Conference Group. The outcomes of children with pediatric acute respiratory distress syndrome: proceedings from the Pediatric Acute Lung Injury Consensus Conference. Pediatr Crit Care Med 2015;16(5 Suppl 1):S118-S131.

18. Zabrocki LA, Brogan TV, Statler KD, Poss WB, Rollins MD, Bratton SL. Extracorporeal membrane oxygenation for pediatric respiratory failure: survival and predictors of mortality. Crit Care Med 2011;39(2):364-370.

19. Arnold JH, Anas NG, Luckett P, Cheifetz IM, Reyes G, Newth CJ, et al. High-frequency oscillatory ventilation in pediatric respiratory failure: a multicenter experience. Crit Care Med 2000;28(12):3913-3919.

20. López-Fernández Y, Azagra AM, de la Oliva P, Modesto V, Sánchez JI, Parrilla J, et al. Pediatric Acute Lung Injury Epidemiology and Natural History study: incidence and outcome of the acute respiratory distress syndrome in children. Crit Care Med 2012;40(12):3238-3245.

21. Peduzzi P, Concato J, Kemper E, Holford TR, Feinstein AR. A simulation study of the number of events per variable in logistic regression analysis. J Clin Epidemiol 1996;49(12):1373-1379.

22. Markovitz BP, Kukuyeva I, Soto-Campos G, Khemani RG. PICU volume and outcome: a severity-adjusted analysis. Pediatr Crit Care Med 2016;17(6):483-489. 